\title{
Alveolar proteinosis: diagnosis and treatment over a 10-year period
}

\author{
RM DU BOIS, WAC MCALLISTER, MA BRANTHWAITE \\ From Brompton Hospital, Fulham Road, London
}

\begin{abstract}
Ten years' experience of using bronchoalveolar lavage in the treatment of 10 patients with alveolar proteinosis is reported. The diagnosis was often missed. The interval between onset of symptoms and diagnosis varied from six weeks to six years (median 2 years), so that the start of treatment was often delayed. Some patients experienced severe progressive disability before they had treatment. Whole-lung lavage proved to be a safe, repeatable procedure which provided symptomatic, physiological, and radiological improvement and allowed all 10 patients treated to return to full-time employment.
\end{abstract}

Pulmonary alveolar proteinosis is a disease of unknown aetiology characterised by the accumulation of protein, phospholipid, cholesterol, and free fatty acids within the alveolar spaces. The diagnosis is confirmed by typical electron-microscopic findings in sputum, lung washings, or lung biopsy specimens, without which the condition is often mistaken for interstitial lung disease, especially sarcoidosis. Alveolar proteinosis can be treated effectively by means of whole-lung lavage, ${ }^{1}$ and we report 10 years' experience of the method-53 lavages in 10 patients - to emphasise the hazards of delay in diagnosis, the safety of bronchopulmonary lavage, and the benefit which results.

\section{Patients and methods}

Ten patients (eight men and two women) aged 23-48 years were referred either for diagnosis (five patients) or for further management (five patients). All were dyspnoeic at rest or on mild exercise and only one, with a sedentary occupation, was still able to work. All were current smokers or ex-smokers.

Measurements were made of dynamic and static lung volumes, airway resistance, gas transfer factor and the transfer coefficient, the results being expressed as percentages of the means of the predicted normal range. ${ }^{2}$ Arterial blood gas tensions were measured at rest with the patient breathing room

Address for reprint requests: Dr RM du Bois, Department of Medicine, Royal Free Hospital, London NW3 2QG.

Accepted 10 January 1983 air. The diagnosis was established by demonstrating characteristic annular, osmiophilic bodies on electron microscopy of sputum if available (three patients), bronchial washings (one patient), or lung biopsy specimens (seven patients).

Bronchopulmonary lavage was performed in each case and was carried out on both sides at least once, with an interval of a few days to several weeks between the treatments according to the severity of the disease. Subsequent lavage was carried out when symptoms recurred if they were accompanied by radiological and functional evidence of deterioration, but treatment more often than once every six months was avoided to minimise the risks of halothane hepatotoxicity.

The method we used was a modification of the technique of Ramirez-R et al ${ }^{1}$ that has been described previously. ${ }^{3}$ In brief, the treated side is isolated during oxygen and halothane anaesthesia by insertion of a Robertshaw double-lumen endobronchial tube. After exclusion from the ventilator circuit the lung is gradually filled with normal saline at $37^{\circ} \mathrm{C}$, buffered to $\mathrm{pH} 7 \cdot 4$, until a volume equal to the calculated functional residual capacity on that side has been introduced. Thereafter aliquots of $500-1000 \mathrm{ml}$ are run in and out until a total of 40 litres has been used or the effluent is clear. After endobronchial suction and vigorous manual ventilation of the treated side, the endobronchial tube is changed to an endotracheal tube and mechanical ventilation is continued for two to four hours to promote re-expansion of the treated side and allow reabsorption of residual fluid. A double-lumen tube with the endobronchial extension entering the left 
Table 1 Clinical features of the patients at presentation

\begin{tabular}{|c|c|c|c|c|c|c|c|c|}
\hline \multirow{2}{*}{$\begin{array}{l}\text { Patient } \\
\text { No }\end{array}$} & \multirow{2}{*}{$\begin{array}{l}\text { Age at } \\
\text { presentation } \\
(y)\end{array}$} & \multirow[t]{2}{*}{ Sex } & \multirow[t]{2}{*}{ Smoking } & \multirow{2}{*}{$\begin{array}{l}\text { Interval between } \\
\text { first symptoms } \\
\text { and diagnosis (y) }\end{array}$} & \multirow{2}{*}{$\begin{array}{l}\text { Interval between } \\
\text { furst radiographic } \\
\text { abnormality and } \\
\text { diagnosis (y) }\end{array}$} & \multicolumn{2}{|l|}{ Signs } & \multirow{2}{*}{$\begin{array}{l}\text { Initial } \\
\text { diagnosis }\end{array}$} \\
\hline & & & & & & Clubbing & $\begin{array}{l}\text { Basal } \\
\text { crackles }\end{array}$ & \\
\hline $\begin{array}{l}1 \\
2\end{array}$ & $\begin{array}{l}23 \\
43\end{array}$ & $\begin{array}{l}\mathbf{F} \\
\mathbf{M}\end{array}$ & $\begin{array}{l}\text { Ex } 2 y \\
\text { Ex } 3 y\end{array}$ & $\begin{array}{l}2 \\
2 / 12\end{array}$ & $\begin{array}{l}2 \\
2 / 12\end{array}$ & \pm & \pm & $\begin{array}{l}\text { Sarcoidosis } \\
\text { Alveolar } \\
\text { proteinosis }\end{array}$ \\
\hline $\begin{array}{l}3 \\
4 \\
5 \\
6\end{array}$ & $\begin{array}{l}39 \\
43 \\
48 \\
44\end{array}$ & $\begin{array}{l}\mathbf{M} \\
\mathbf{F} \\
\mathbf{M} \\
\mathbf{M}\end{array}$ & $\begin{array}{l}\text { Ex } 11 / 2 \text { y } \\
20 \mathrm{cpd} \\
\text { Pipe } \\
40 \mathrm{cpd}\end{array}$ & $\begin{array}{l}6 / 12 \\
6 \\
3 \\
2\end{array}$ & $\begin{array}{l}1 / 12 \\
4 \\
3 / 12 \\
2\end{array}$ & $\begin{array}{l}- \\
\overline{+} \\
+\end{array}$ & $\begin{array}{l}+ \\
- \\
-\end{array}$ & $\begin{array}{l}\text { Sarcoidosis } \\
\text { Sarcoidosis } \\
\text { Tuberculosis } \\
\text { Pulmonary } \\
\text { fibrosis }\end{array}$ \\
\hline 7 & 25 & $\mathbf{M}$ & $25 \mathrm{cpd}$ & $8 / 12$ & $8 / 12$ & + & - & $\begin{array}{l}\text { Extrinsic } \\
\text { allergic } \\
\text { alveolitis }\end{array}$ \\
\hline 8 & 25 & $\mathbf{M}$ & Occasional & $6 / 12$ & $4 / 12$ & + & - & $\begin{array}{l}\text { Alveolar } \\
\text { proteinosis }\end{array}$ \\
\hline $\begin{array}{r}9 \\
10\end{array}$ & $\begin{array}{l}35 \\
28\end{array}$ & $\begin{array}{l}\mathbf{M} \\
\mathbf{M}\end{array}$ & $\begin{array}{l}\text { Pipe } \\
20 \text { cpd }\end{array}$ & $\begin{array}{l}3 \\
2 \\
3 / 12\end{array}$ & $\begin{array}{l}24 \\
23 / 12\end{array}$ & $\overline{-}$ & \pm & $\begin{array}{l}\text { Sarcoidosis } \\
\text { Sarcoidosis }\end{array}$ \\
\hline
\end{tabular}

Ex-ex-smoker of at least one year's duration; cpd-cigarettes per day.

main bronchus ensures more reliable separation of the two sides than does a left-sided or right-sided tube (depending on which side is to be treated). The electrocardiagram and arterial blood pressure are monitored throughout, but arterial cannulation and blood gas analysis are only routinely undertaken during the initial treatment of patients who are dyspnoeic at rest or who have an arterial oxygen tension (while breathing air) of less than $6.6 \mathrm{kPa}$ (50 $\mathrm{mm} \mathrm{Hg})$.

\section{Results}

The interval between the onset of symptoms and diagnosis varied from six weeks to six years (median two years), and the two most seriously disabled patients were confined to bed and receiving continuous oxygen before the diagnosis was established. The symptoms were non-specific, usually comprising progressive breathlessness without variation or wheeze, but often accompanied by a dry cough.

Table 2 Respiratory data before whole-lung lavage

\begin{tabular}{llllc}
\hline Patient No & $\begin{array}{l}\text { VC } \\
\text { (\% pred) }\end{array}$ & $\begin{array}{l}\text { TLC } \\
\text { (\% pred) }\end{array}$ & $\begin{array}{l}\text { TLCO } \\
\text { (\% pred) }\end{array}$ & $\begin{array}{l}P_{2}(\mathrm{kPa}) \\
\text { (room air) }\end{array}$ \\
\hline 1 & 33 & 35 & 16 & 3.73 \\
2 & 75 & 77 & 67 & 9.87 \\
3 & 58 & 58 & 34 & 10.93 \\
4 & 64 & 57 & 25 & 5.2 \\
5 & 86 & 89 & 74 & 12.67 \\
6 & 71 & 80 & 48 & 10.67 \\
7 & 35 & 49 & 31 & 6.0 \\
8 & 60 & 66 & 39 & $9 \cdot 07$ \\
9 & 70 & 69 & 52 & 10.93 \\
10 & 77 & 76 & 56 & 12.0 \\
\hline
\end{tabular}

VC-vital capacity; TLC-total lung capacity; TLCO-transfer factor.

Conversion: $\mathrm{SI}$ to tradition units-oxygen tension $\left(\mathrm{PO}_{2}\right): 1 \mathrm{kPa}=$ $7.5 \mathrm{~mm} \mathrm{Hg}$.
Spontaneous remission was not a feature in any of our cases before treatment, though the severity of radiological change fluctuated in one patient. Six had been treated with corticosteroids for presumptive sarcoidosis (without histological confirmation) before the correct diagnosis was established and one had received antituberculous chemotherapy for 10 months. The clinical features at presentation to this hospital are summarised in table 1 ; there were no abnormal signs in four patients; three had finger clubbing alone, two had bilateral basal crackles, and one had both finger clubbing and bilateral basal crackles.

The results of lung function tests before treatment are shown in table 2 . All patients had a restrictive ventilatory defect but the severity showed considerable variation between patients. All had a low transfer factor but six of the 10 patients maintained a resting arterial oxygen tension above $10.7 \mathrm{kPa}(80$ $\mathrm{mm} \mathrm{Hg}$ ). The initial chest radiograph showed diffuse nodular shadowing with confluence, predominantly affecting the mid zones. In seven patients abnormal shadows were seen throughout both lungs. The abnormal appearances were symmetrical in five, predominantly central, resembling pulmonary oedema, in three and predominantly peripheral in one. Lung volume (assessed radiologically) appeared small in three of the 10 subjects. Haematological and biochemical investigation of the blood was unhelpful. The erythrocyte sedimentation rate ranged from 1 to $38 \mathrm{~mm}$ in the first hour; seven of the 10 patients had raised levels of IgM alone but none had serological evidence of autoimmune disease. Liver cellular enzymes were increased in five patients, with a raised bilirubin concentration in two.

Details of the number of lavages and the duration 
Table 3 Duration follow-up and numbers of lavages during follow-up

\begin{tabular}{lcc}
\hline Patient No & No of lavages & Follow-up $(y)$ \\
\hline 1 & 9 & $8^{*}$ \\
2 & 2 & ${ }^{*}$ \\
3 & 2 & $0 \cdot 83$ \\
4 & 3 & $0 \cdot 75$ \\
5 & 11 & 8 \\
6 & 2 & 10 \\
7 & 4 & 7 \\
8 & 12 & 9 \\
9 & 6 & 7 \\
10 & 2 & 1 \\
\hline
\end{tabular}

*Now has multiple sclerosis; follow-up elsewhere.

†Emigrated to Canada.

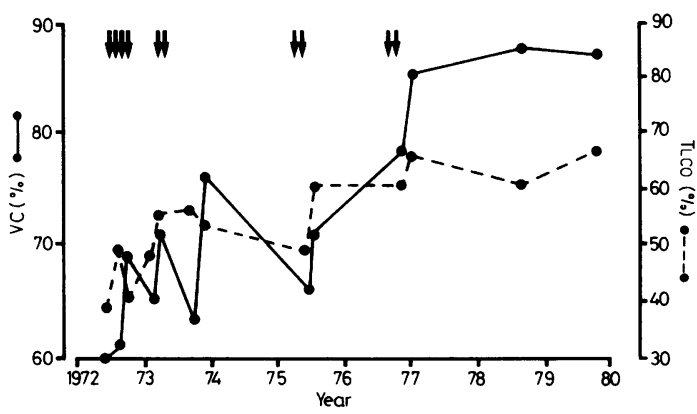

Fig 1 Changes in vital capacity (VC) and transfer factor $(T L C O)$ in a single patient during eight years, expressed as percentages of the means of the normal ranges. Arrows indicate dates of lavage.

of follow-up are given in table 3 and a representative progress chart for an individual patient is shown in figure 1. Symptomatic improvement followed each treatment within 24 hours, and a normal exercise tolerance was restored in all patients after both lungs had been treated from one to three times over a period of a few months. All patients returned to work, although one has since developed multiple sclerosis.

Radiological improvement was less impressive immediately after lavage, although some clearing was usually apparent within a few days. Progressive radiological clearing was observed in one patient during the two years after his final lavage. In another patient, who had been lost to follow-up for 10 years, comparison of radiographs taken at the beginning and end of this period showed that residual shadowing had resolved. Functional improvement has been documented in all patients (fig 2 ) and has been sustained in some for several years without further treatment.

Morbidity after treatment has been low: one patient developed rigor within 24 hours and pneumococci were isolated from the sputum. His
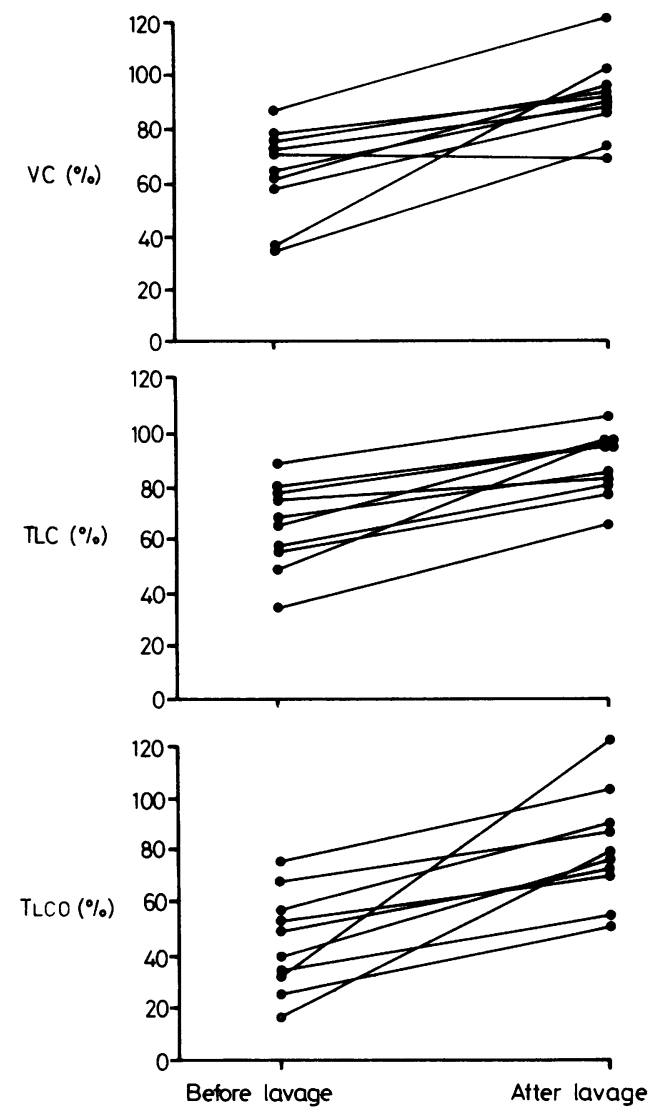

Fig 2 Comparison of mean values of vital capacity (VC), total lung capacity (TLC), and transfer factor (TLCO) before and after lavage, expressed as percentages of the means of the normal ranges.

condition improved rapidly with antibiotic treatment and he has tolerated lavage on subsequent occasions without incident. An increase in dyspnoea associated with airflow limitation occurred in one patient but this responded promptly to inhaled salbutamol. One patient was hoarse for 36 hours after difficult endobronchial intubation.

\section{Discussion}

Pulmonary alveolar proteinosis is a rare disorder but one in which early diagnosis can result in rapid improvement after treatment by whole-lung lavage. Ramirez- $\mathrm{R}^{4}$ was the first to describe long-term follow-up of six patients and emphasised that repeated lavage was beneficial and safe. More recently Rogers $e t$ al $^{5}$ reported data on 14 patients followed for up to 96 months. All 14 patients were improved by lavage, and when repeat lavage was necessary 
clinical and physiological improvement was again obtained.

The non-specific clinical and investigative features mean that the diagnosis is easy to miss, and in our series it was delayed for up to six years from the onset of symptoms. This delay resulted in severe hypoxaemia in three patients and notable disability in all. Six patients received inappropriate treatment with corticosteroids. Davidson and Macleod 6 reviewed the published reports and found that $27 \%$ of deaths were a direct result of infective complications, fungal infection being common. Inappropriate corticosteroid treatment could increase this hazard, although in our series no infective complications of inappropriate treatment were encountered. Diagnostic bronchoalveolar lavage can confirm the diagnosis, however, by yielding characteristic lamellar bodies visible on electron microscopy, ${ }^{3}$ and early use of this technique could minimise delay.

Whole-lung lavage has now superseded antibiotics, iodides, streptokinase, and aerosolised trypsin as the treatment of choice, and has been carried out safely and repeatedly in this series. One patient who required repeated lavage suffered a myocardial infarction during follow-up; but since then lavage has been carried out uneventfully on several occasions, though we waited for a year after the infarction. There are several reasons why the risks associated with the procedure are small provided that the two lungs are isolated satisfactorily. The arterial oxygen tension falls only slowly, allowing time for compensatory mechanisms to operate; there is no tendency for respiratory function to change suddenly during the procedure; and the metabolic demand is not increased as a result of the disease and is actually reduced during anaesthesia. A high inspired oxygen concentration can be maintained throughout in the ventilated lung and perfusion to the opposite lung is probably reduced during the lavage. We have therefore never considered it necessary to use cardiopulmonary bypass. Although at first arterial oxygen tension, electrolyte concentrations, and central venous pressure were monitored closely throughout the procedure, experience has shown that this is unnecessary in all but high-risk patients. Even then the arterial oxygen tension throughout the procedure is usually higher than the pretreatment value for that patient breathing air. Freedman et $\mathrm{al}^{7}$ report the case history of one patient and discuss two other patients in whom cardiopulmonary bypass was used during lavage. The resting arterial oxygen tension during the breathing of room air was $27 \mathrm{~mm} \mathrm{Hg}(3.60 \mathrm{kPa})$ in two patients and $28 \mathrm{~mm} \mathrm{Hg}(3.73 \mathrm{kPa})$ in the third, and it was because of the severity of the hypoxia that bypass was thought to be necessary. Two patients in our series had similar lowest values for arterial oxygen tension but cardiopulmonary bypass was thought unnecessary for the reasons given above. Uneventful and successful lavage was subsequently carried out in both of these patients.

Response to treatment has varied in degree, though all patients were improved symptomatically, radiologically, and functionally. Some have continued to improve spontaneously after an initial response to lavage but others have required repeated lavage.

Defective clearance of alveolar secretion has been postulated as the cause of the condition ${ }^{8}$ but the nature of the defect has not been identified and specific treatment has not yet been devised. We believe that control of symptoms by means of early treatment with whole-lung lavage is acceptable, safe, and successful.

We are indebted to Professor Margaret TurnerWarwick, Dr P Cole, and Dr EE Keal for allowing us to report on patients under their care. We thank Miss T Chudleigh for typing this manuscript.

\section{References}

' Ramirez-R J, Kieffer RF, Ball WC. Bronchopulmonary lavage in man. Ann Intern Med 1965;63:819-28.

${ }^{2}$ Cotes JE. Lung function: Assessment and application in medicine. 4th ed. Oxford, Blackwell Scientific Publications, 1979.

${ }^{3}$ Costello JF, Moriarty DC, Branthwaite MA, TurnerWarwick M, Corrin B. Diagnosis and management of alveolar proteinosis: the role of electron microscopy. Thorax 1975;30:121-31.

${ }^{4}$ Ramirez-R J. Alveolar proteinosis: importance of pulmonary lavage. Am Rev Respir Dis 1971;103:666-78.

${ }^{5}$ Rogers RM, Levin DC, Gray BA, Mosely LW Jr. Physiologic effects of bronchopulmonary lavage in alveolar proteinosis. Am Rev Respir Dis 1978;118:255-64.

${ }^{6}$ Davidson JM, Macleod WM. Pulmonary alveolar proteinosis. Br J Dis Chest 1969;63:13-25.

' Freedman AP, Pelias A, Johnston RF, Goel IP, Hakki HI, Oslick T, Shinnick JP. Alveolar proteinosis lung lavage using partial cardiopulmonary bypass. Thorax 1981;36:543-5.

${ }^{8}$ Ramirez-R J, Harlan WR Jr. Pulmonary alveolar proteinosis: nature and origin of alveolar lipid. $A m \mathrm{~J}$ Med 1968;45:502-12. 